\title{
VOLUNTARY CONTRIBUTION GAMES: EFFICIENT PRIVATE PROVISION OF PUBLIC GOODS
}

\author{
MARK BAGNOLI and MICHAEL MCKEE*
}

\begin{abstract}
This paper reports on a series of laboratory experiments designed to evaluate a mechanism for the voluntary provision of public good. The public good is provided if the total contributions meet or exceed a threshold and all contributions are returned if the public good is not provided. The members of the group all know the threshold, the incomes, and the valuations assigned the public good by all other members. The results support the prediction that this mechanism will yield Pareto efficient outcomes and suggest that economic agents adopt strategies which form equilibria satisfying certain refinements to the Nash equilibrium.
\end{abstract}

\section{INTRODUCTION}

In 1979 the Association of Oregon Faculties wished to raise money to hire a lobbyist at the state legislature. It was known that the output of this lobbyist would be a public good since any salary increases obtained as a result of the lobbying activity would accrue to all faculty in the state. The question was, how to pay the lobbyist's salary $(\$ 30,000)$. The Association asked all faculty in the state for individual contributions, giving guidelines according to salary. Further, the Association stipulated that all contributions would be returned if the $\$ 30,000$ was not raised by a specified date. The lobbyist was hired. ${ }^{1}$ In 1980, and again in 1985, the New Democratic Party (NDP) in Manitoba, Canada

\footnotetext{
* Indiana University and University of New Mexico respectively. Earlier versions of this paper were presented at the 1986 meetings of the Canadian Economics Association, the 1987 joint meetings of the Public Choice Society and the Economic Science Association and at seminars at a number of universities. We thank all participants for their comments. We would especially like to thank James AIm, Jim Andreoni, Ted Bergstrom, Ken Binmore, Norman Frohlich, Glenn Harrison, Mark Isaac, Bart Lipman, and Steve Salant for reading earlier drafts and providing many useful comments. Tom Borcherding and an anonymous referee made certain we told our story well; we are grateful to both. Funding was provided by the Social Sciences and Humanities Research Council of Canada and the University of Windsor.
}

1. This incident is recounted in Dawes et al. [1986]. sent letters to its larger contributors soliciting additional funds to mount a coming election campaign. The letters described those being canvassed (large donors), explained the issues in the coming election and the NDP's proposed policy stance, and explained how the money was to be used. Further, the letters stipulated that a target had been set $(\$ 200,000$ in 1980 and $\$ 250,000$ in 1985) and that the NDP would refund all contributions if the target was not reached by a certain date. Both campaigns were successful, and in 1985 the total contributions were $\$ 251,300$, or $1 / 2$ percent more than the target. ${ }^{2}$ In 1986 a ski facility near Boulder, Colorado went into bankruptcy. At a general meeting the local Nordic Ski Club announced to its members that it wished to maintain the Nordic portion of the facility and that this would require raising some announced amount of money from the members to pay for trail upkeep. If the total contributions were insufficient to keep the facility open, the members would have their monies refunded and the facility would be allowed to close down. The Nordic facility was successfully operated until 1988 when a

2. This information was provided by Ron Cavalucci of the Manitoba NDP. There was only one mailing and no follow up contact was made with the donors. 
private firm purchased the entire facility and restored both the downhill and Nordic operations. ${ }^{3}$

Such successes in obtaining voluntary contributions to the provision of a public good stand in contrast to the predictions of Samuelson [1954] and many other economists who suggest that individuals would not voluntarily contribute toward the provision of public goods owing to the incentive to free ride. More recently, a large literature has emerged which presents theoretical and empirical evidence mitigating this conclusion. Generally this literature shows that voluntary provision of public goods may be greater than zero, in certain cases, but inefficient. ${ }^{4}$ In this paper we evaluate a particular class of public goods provision mechanisms which capture the important characteristics of the anecdotes related above.

Those donating to the salary of the lobbyist, the election campaign, and the ski facility were all engaged in a voluntary contribution game for the provision of a public good. These situations have several features in common. In each case the public good could be produced only if the sum of the contributions met or exceeded some threshold, and this threshold, the cost of the collective good, was known to the individuals being asked to contribute. The total number of individuals in the consuming group was known, with more or less precision, by the individuals involved. By introspection, each individual could infer something of the valuations held by those being asked to contribute. No one would be excluded from consuming the public good on the grounds that he or she had not contributed to its provision. Finally, if the sum of the contributions fell short of the threshold, each individual would have his or her contribution

3. Bill Schulze, a member of the club, provided us with the details of this incident.

4. We report on some of this literature in the next section. returned.

Dawes et al. [1986] and van de Kragt et al. [1983] have studied public good contribution games in laboratory settings which are similar to those described above. In their "minimum contributing set" (MCS) institutions, individuals may choose to contribute all of their wealth, or not, to the provision of a public good under the rule that the good will be supplied if a pre-announced number (smaller than the entire group) of individuals contribute. If fewer individuals contribute, the good is not supplied and the contributions are returned. In laboratory settings, the MCS regime is largely successful in generating the efficient outcome; when it is Pareto optimal for the good to be provided, it is. Palfrey and Rosenthal [1984] investigated the MCS setting and found some theoretical support for these results.

The MCS regime places the individuals in a binary decision setting; they must choose whether or not to contribute their entire wealth to the provision of the public good. This leads to the presence of redistributive effects, which the individuals must resolve while also trying to have the public good supplied. These effects will reduce the likelihood that the equilibrium outcome will be the one which has the collective good supplied.

In each of the above anecdotes the individuals were free to choose the level of their contribution from zero up to their entire wealth, in contrast to the MCS settings. Bagnoli and Lipman [1989] investigate such a voluntary contribution game and show that individual agents have sufficient incentives to voluntarily achieve the Pareto efficient outcome; that is, individually rational behavior will lead to the efficient provision of the public good through purely voluntary contributions.

The theoretical argument of Bagnoli and Lipman is persuasive, but there is a strong need for empirical investigation of their prediction. They show that there are many possible equilibria, but only an im- 
portant subset of these result in the Pareto efficient solution. Thus, it is necessary to investigate whether individuals are capable of focussing on one of the efficient equilibria in the contribution game setting. This is particularly important in settings when, as in Bagnoli and Lipman, the individual agents' chosen strategies are assumed to satisfy some "refinement" to the Nash equilibrium concept.

Refinements serve to reduce the set of admissible equilibrium outcomes by imposing some additional structure on individual choices or strategies. As van Damme [1983] demonstrates, refinements are invoked when the set of Nash equilibria contains outcomes that can be thought of as not being "sensible" behavior. Game theorists generally depend on introspection to arrive at a definition of sensible behavior. Ultimately, this is a behavioral phenomenon and it is necessary to subject it to empirical investigation.

We conduct our empirical investigations in a laboratory setting where our experimental sessions implement exactly the contribution game as described by Bagnoli and Lipman. We have data for seven replications with groups of five persons and two replications with groups of ten persons; all groups played the game for fourteen periods. In the last five periods the groups are almost universally successful in having the public good provided; we observe one failure (of thirty-five possible observations) to provide the public good in a five-person group and one failure (of twenty possible observations) in a ten-person group. 5

It is likely the groups described in each of the anecdotes at the beginning of this

5. We report results for the last five periods in response to the concerns raised by Isaac, McCue, and Plott [1985] who argued that subjects in an experiment needed time to "learn the game" since contributing to a collective good in this environment is likely to be an infrequent activity for most people. An obvious alternative interpretation is that repetitions are needed to focus on an equilibrium. paper were comprised of individuals with differing valuations for the public good and with different initial wealths. To investigate the effects of such heterogeneity, some of our replications involve groups whose members have different valuations for the public good or different initial wealth. We find that groups for which the differences in wealth or valuations are considerable are as capable of providing the public good as the group that was comprised of individuals with identical wealths and valuations. We find also that increasing the number of persons in the group slows the rate at which the group is able to focus on an equilibrium. However, this latter result must be considered preliminary until both more replications are run and even larger groups are studied.

Our current work serves two purposes. The first is to evaluate a particular public good provision mechanism. The second is to investigate the behavioral usefulness of certain refinements which have appeared in the game theory literature in recent years.

\section{THE THEORY OF THE CONTRIBUTION GAME}

Bagnoli and Lipman [1989] provide the complete theoretical discussion of their contribution game. ${ }^{6}$ Here we present the intuition behind their predictions with the aid of a simple example having the essential characteristics of the public good contribution game we are investigating.

Consider the decision to build a neighborhood playground. ${ }^{7}$ There are three

6. Interested readers are referred to their paper for a full discussion of the details.

7. We are studying the provision of public goods which have the characteristic that exclusion is not feasible. Thus, we are not addressing the questions raised by Coase [1974] in his discussion of private provision of lighthouse services, nor are we considering the general cases studied by Thompson [1968], Demsetz [1970], and Borcherding [1978], all of whom focussed on the class of public goods where exclusion was possible. 
families in this neighborhood whose willingness to pay for the playground is five, ten, and twenty dollars respectively. The playground costs twenty-five dollars to build and there is no possibility of building a fraction of a playground. ${ }^{8}$ It is the case that each family's wealth exceeds its valuation of the playground. All of this information is common knowledge to the three families. The playground must be financed entirely from the voluntary contributions of the three families. One version of such a "contribution game," consistent with Bagnoli and Lipman's model, has the playground provided if the sum of the contributions meets, or exceeds, the cost (twenty-five dollars). All contributions in excess of twenty-five dollars are kept ${ }^{9}$ and, in the event the contributions fall short of twenty-five dollars, the playground is not provided and all contributions are returned. ${ }^{10}$

This example is constructed so that building the playground is the Pareto efficient outcome, but no one family would choose to build the playground on its own. Bagnoli and Lipman prove that the only sensible equilibria are those for which the contributions sum to exactly twenty-five dollars (the cost of the playground) and no family contributes more than its willingness to pay. ${ }^{11}$ Two such

8. Thus, our public good provision setting differs from the Cournot reaction settings studied by Cornes and Sandler [1985a; 1985b] and by Bergstrom, Blume, and Varian [1986]. Our setting also differs from the continuous public good models as investigated by Isaac, McCue, and Plott [1985].

9. Actually, excess contributions may be returned so long as it is done in such a manner that the households cannot increase their refund by their choice of contribution. See Bagnoli and Lipman [1989].

10. Clearly other institutions are possible. See Palfrey and Rosenthal [1984]. The contributions could be kept even if the good is not provided. As Bagnoli and Lipman [1989] point out, such arrangements may lead to inefficient outcomes.

11. They actually prove the stronger result that all sensible outcomes are in the core described by Shubik [1982]. equilibria are: $(0,6,19)$ and $(25 / 7,50 / 7$, $100 / 7)$. The former is an inequitable division of the burden while the latter is an "equitable" division of the burden since each family pays the same fraction of its valuation. In both, no family will reduce its contributions since the playground will not then be built.

To explain which vectors of contributions form an equilibrium and which do not, we proceed in three steps. First we argue that total contributions cannot exceed twenty-five dollars in equilibrium. Second, we argue that total contributions equal to twenty-five dollars are equilibrium outcomes; and, finally, we argue that total contributions less than twenty-five dollars are equilibria but are not sensible outcomes.

Suppose that contributions are $(3,6,19)$ which clearly sum to more than twentyfive dollars. If any family reduces its contribution by one dollar, the playground is still built and that family is better off by the one dollar. Thus $(3,6,19)$ is not a Nash equilibrium. This reasoning can be applied to all cases in which the total contributions exceed the cost of the playground.

Now suppose that contributions are $(0$, $6,19)$. These sum to twenty-five dollars and no family is contributing more than its valuation of the playground. This outcome is a Nash equilibrium since no family will want to unilaterally reduce its contribution. Such a reduction will result in no playground being built. Consequently, any family reducing its contribution is worse off since it loses the difference between its valuation and its contribution; a positive amount by definition. Contributing more is simply giving away money. Hence, if the total contributions are twenty-five dollars, no family can unilaterally alter its contribution and make itself better off. Thus $(0,6,19)$ is a Nash equilibrium. We can use similar reasoning to show that any vector of contributions summing to twenty-five dollars, and having no family's contribution exceed its valua- 
tion, is a Nash equilibrium. Further, it is a strong Nash equilibrium in the sense that each family's optimal contribution, given all other family's contributions, is unique.

Lastly, suppose contributions are $(0,0$, $0)$. We need to show that this is a Nash equilibrium but that it is not sensible. It is clear that no family can contribute less, so let us consider whether any family will wish to contribute more on its own. For a change in contribution to affect a family's payoff, it must lead to the playground being provided. The playground will be provided if one family contributes twentyfive dollars, but this amount exceeds the valuation of each of our families, and so no family will choose to contribute twenty-five dollars. Hence $(0,0,0)$ is a Nash equilibrium. Using similar reasoning, Bagnoli and Lipman show that any vector of contributions summing to less than twenty-five dollars and having the property that the sum would still be less than twenty-five if any one family chose to contribute its entire valuation, is a Nash equilibrium.

To see that such outcomes are not sensible, suppose that there is a small chance (probability) that the second family will contribute eight dollars and the third family will contribute sixteen dollars. Then the first family ought not to contribute zero. By contributing one dollar, if the other families contribute eight and sixteen respectively, the first ensures that the playground is provided and obtains a four dollar payoff for itself. If either the second or third family actually contributes zero, the first family is no worse off than if it had actually contributed zero because contributions are refunded if the total is less than twenty-five. Thus, for any small probability of the contributions from the second and third families being eight and sixteen dollars respectively, zero is not an optimal choice for the first family. Analogous reasoning can be used to show that anytime the contributions fail to sum to twenty-five, someone has played a strat- egy that is not sensible. ${ }^{12}$

In our experiments we study the behavior of individuals, in a group of five or ten persons, faced with the task of contributing to the provision of a single unit of a public good. For the five-person groups the cost of the good is set at 12.5 "tokens" and the sum of the individual valuations is twenty-five "tokens," making it Pareto efficient that the good be provided. ${ }^{13}$ In our base case we have the symmetric setting in which each individual's initial wealth is ten "tokens" and each has a valuation of five "tokens" for the public good. At this stage we want to investigate the contribution game exactly as presented in the theory. In keeping with the assumptions of Bagnoli and Lipman, all of the above information is common knowledge to the subjects.

Our laboratory setting, like our playground example, provides the most interesting class of situations, for here it is efficient to have the public good provided and we confront the usual free riding argument.

\section{THE EXPERIMENTAL DESIGN}

Our experimental environment reproduces the features of the theoretical setting described above and in Bagnoli and Lip-

12. The proofs are provided, in all their gory detail, in Bagnoli and Lipman [1989]. The reasoning attributed to the families in our example serves to eliminate equilibria that are counter-intuitive. The particular form of the reasoning forms the basis of the refinement Selten [1975] calls "trembling hand perfect" equilibria, applied after eliminating dominated strategies. Imagine there are two players in a game. Each chooses a strategy by pressing a button, but each player is subject to a nervous condition which causes his hand to tremble when he reaches for the button he wishes to push. Because there is some probability of an error, each player will choose a strategy which is the best reply to the strategy he thinks the other will play and also to strategies which are small mistakes due to trembles. The resulting outcome is called a perfect equilibrium.

13. In the ten-person groups the corresponding numbers are twenty-five for the cost and fifty for the aggregate valuation. 
man. ${ }^{14}$ Subjects enter the room where the experiment is to be conducted and are assigned to groups in a random fashion. ${ }^{15}$ The person conducting the session reads the instructions (appendix A) aloud while the subjects follow on their own instruction sheets. The instructions inform the subjects that their task is to choose their contribution to the provision of a good which the entire group will share. We use a "token currency" for the experiments, and this is converted to dollars at an exchange rate announced at the beginning of the session. This procedure follows the "induced value" method of Smith [1976] in which the subjects exchange commodities which have value only because the experimenter has pledged to redeem the commodity for cash. This method provides the person running the experiment maximum possible control over preferences by setting the structure of the exchange rate between tokens and dollars. The public good is described as an additional bundle of tokens to be shared among the members of the group according to a pre-announced sharing rule.

Each subject receives an information slip for each period or round of the experimental session. This slip provides the information prescribed by the theory-complete information on the wealth and public good valuations of the members of the group, the size of the group, and the cost of the good-and provides the subject a

14. We stress this point since we feel that it has often been overlooked in the experimental literature. It is essential the experimental subjects be provided with exactly the information attributed to the players in the game being investigated in the theory. In order to know his best choice from the available strategies a player must conjecture the choice of his opponent(s). To do this, the player must be informed of the payoffs of his opponents to each available strategy.

15. The room in which the sessions were conducted is very large allowing the subjects to be seated a considerable distance from each other. Student assistants collected and distributed the information slips used by the subjects. space to enter his contribution to the public good. Specifically, the information slips tell the subject: (1) the number of people in his group, but not their identities, (2) his own income, (3) the incomes of the others in the group, (4) the cost of the public good, and (5) the payoff to each member of the group if the public good is provided. Further, the subjects are told that the experiment will last for fourteen periods or rounds, that they will remain in the same group for the entire session, and that conditions (2) through (5) will remain constant for the duration of the experimental session. The subjects are required to choose their contributions simultaneously-without knowledge of the contributions of the others in their group. The subjects play a game of complete but imperfect information.

We conducted all experiments over two sessions during which we ran seven replications with five-person groups and two replications with ten-person groups. Both sessions ran for fourteen periods and included a ten-person group as well as several five-person groups. For each of the five person groups (assigned group numbers 11 through 17) the cost of the public good, referred to as the "threshold contribution level," was set at 12.5 tokens. The value of the public good, the additional bundle of tokens, was set at twenty-five tokens; that is, the increase in the social welfare from the provision of the public good was $12.5(25-12.5)$ tokens. For the ten-person groups (group numbers 20 and 21), the threshold contribution level was twenty-five tokens and the additional bundle of tokens was set at fifty.

Group 11 constitutes our base case. All members of this group have the same initial induced wealth and valuation of the public good. To investigate the effects of heterogeneous group membership, we conducted two treatments. In the first, we held the distribution of valuations of the public good constant (each subject receiving the same share) and varied the initial 
distribution of induced wealth across groups 12,13 , and 14 . In the second treatment we held the initial distribution of income constant (each member of the group receiving the same initial income) while varying the distribution of valuations of the public good across groups 15, 16, and 17. Group 20 constitutes our base case for the ten-person groups. For group 21 the valuations were identical across all members but the initial wealth was not. The complete set of incomes and valuation used in our experiments is reported in appendix A.

We recruited our subjects from undergraduate classes at the University of Michigan and the University of Windsor. The sessions lasted approximately one hour and the average payoffs were between $\$ 18.00$ and $\$ 20.00$.

\section{EXPERIMENTAL HYPOTHESES AND RESULTS}

The theory suggests three testable hypotheses concerning the behavior of the subjects in our laboratory sessions. Bagnoli and Lipman's theorem asserts that the public good will be provided via voluntary contributions when the sum of the valuations exceeds the cost of the good. Otherwise, the good will not be provided. Thus, our first hypothesis may be stated:

\section{HYPOTHESIS 1: When the sum of valuations} exceeds the cost, the public good will be provided and the contributions will sum to the cost exactly.

There are two possible ways for the experimental data to refute this hypothesis. The contributions may sum to less than the cost of the good and the good not be provided as a result, or the good may be provided but the contributions sum to more than the cost of the good.

Individual rationality requires that each subject offer to contribute no more than his or her valuation for the good. Thus our second hypothesis is:
HYPOTHESIS 2: No subject will contribute more than his valuation since this is the maximum he can obtain from the provision of the good.

Bagnoli and Lipman's theorem holds independently of the number of households. As a practical matter, most would believe that the free rider problem becomes more severe as the size of the group increases. As the number of households increases, the effect of any one choosing not to contribute becomes negligible. Hence, as the numbers get large, voluntary provision must become less efficient. Bagnoli and Lipman show that this is not the case for their contribution game. In the equilibrium all contributors are pivotal since the sum of the contributions is exactly equal to the cost. If any one household reduces its contribution, no matter how small to begin with, total contributions will fall below the cost and the public good will no longer be supplied. Thus we have our third hypothesis:

HYPOTHESIS 3: Group size has no impact on the ability of the group to reach the Pareto efficient equilibrium level of contributions.

Testing this hypothesis is limited by our budget constraint, but we have conducted experimental sessions with groups of size five and of size ten.

Table I reports the total contributions for each group for each period. Comparing the total contributions to the cost provides the clearest test of hypothesis 1 . Further, since we have induced all values held by our subjects as part of our design, we can compute social welfare levels for all groups. These data are reported in Table II. The theoretical welfare maximum is defined to be the sum of the valuations of all members of the group plus their initial wealth minus the sum of the contributions at the predicted equilibrium. When the group is successful in having the good provided, actual social welfare is computed as the sum of the valuations plus 
TABLE I

Total Contributions by Group-in Tokens

\begin{tabular}{|c|c|c|c|c|c|c|c|c|c|}
\hline \multirow[b]{2}{*}{ Period } & \multicolumn{9}{|c|}{ Group Number } \\
\hline & 11 & 12 & 13 & 14 & 15 & 16 & 17 & 20 & 21 \\
\hline 1 & 20.0 & 10.5 & 15.0 & 12.5 & 17.0 & 24.0 & 18.0 & 38.0 & 29.5 \\
\hline 2 & 14.5 & 13.0 & 11.0 & 12.5 & 15.2 & 16.5 & 14.1 & 28.5 & 25.5 \\
\hline 3 & 12.0 & 12.5 & 14.5 & 12.5 & $\mathbf{1 1 . 5}$ & 12.0 & 13.2 & 23.3 & 25.0 \\
\hline 4 & 13.0 & 12.0 & 13.5 & 12.5 & 10.0 & 12.0 & 12.5 & 17.2 & 24.0 \\
\hline 5 & 12.5 & 12.5 & 11.0 & 12.5 & 13.5 & 15.0 & 12.5 & 23.5 & 19.5 \\
\hline 6 & 12.0 & 10.0 & 12.5 & 12.5 & 12.8 & 14.0 & 12.5 & 25.5 & 23.5 \\
\hline 7 & 12.5 & 13.0 & 12.5 & 12.5 & 12.8 & 13.5 & 12.5 & 25.5 & 24.5 \\
\hline 8 & 12.5 & 12.5 & 12.0 & 12.5 & 12.5 & 13.0 & 12.5 & 26.5 & 26.5 \\
\hline 9 & 12.5 & 13.0 & 12.5 & 12.5 & 12.5 & 13.5 & 12.5 & 24.0 & 25.0 \\
\hline 10 & 12.5 & 12.3 & 12.5 & 12.5 & 12.5 & 13.0 & 12.5 & 25.2 & 26.0 \\
\hline 11 & 12.5 & 13.0 & 12.5 & 12.5 & 12.7 & 13.0 & 12.5 & 24.25 & 25.0 \\
\hline 12 & 12.5 & 12.0 & 12.5 & 12.5 & 12.5 & 13.0 & 12.5 & 25.0 & 25.0 \\
\hline 13 & 12.5 & 12.5 & 12.5 & 12.5 & 12.5 & 13.0 & 12.5 & 25.0 & 25.0 \\
\hline 14 & 12.5 & 13.0 & 12.5 & 12.5 & 12.5 & 12.5 & 12.5 & 25.0 & 28.5 \\
\hline
\end{tabular}

TABLE II

Welfare Levels

\begin{tabular}{|c|c|c|c|c|c|c|c|c|c|}
\hline \multirow[b]{2}{*}{ Period } & \multicolumn{9}{|c|}{ Group Number } \\
\hline & 11 & 12 & 13 & 14 & 15 & 16 & 17 & 20 & 21 \\
\hline 1 & 60.0 & 55.0 & 65.0 & 67.5 & 63.0 & 56.0 & 62.0 & 122.0 & 130.5 \\
\hline 2 & 65.5 & 67.0 & 55.0 & 67.5 & 64.8 & 63.5 & 65.9 & 131.5 & 134.5 \\
\hline 3 & 55.0 & 67.5 & 65.5 & 67.5 & 55.0 & 55.0 & 66.8 & 110.0 & 135.0 \\
\hline 4 & 67.0 & 55.0 & 66.5 & 67.5 & 55.0 & 55.0 & 67.5 & 110.0 & 110.0 \\
\hline 5 & 67.5 & 67.5 & 55.0 & 67.5 & 66.5 & 65.0 & 67.5 & 110.0 & 110.0 \\
\hline 6 & 55.0 & 55.0 & 67.5 & 67.5 & 67.2 & 66.0 & 67.5 & 134.5 & 110.0 \\
\hline 7 & 67.5 & 67.0 & 67.5 & 67.5 & 67.2 & 66.5 & 67.5 & 134.5 & 110.0 \\
\hline 8 & 67.5 & 67.5 & 55.0 & 67.5 & 67.5 & 67.0 & 67.5 & 133.5 & 133.5 \\
\hline 9 & 67.5 & 67.0 & 67.5 & 67.5 & 67.5 & 66.5 & 67.5 & 110.0 & 135.0 \\
\hline 10 & 67.5 & 55.0 & 67.5 & 67.5 & 67.5 & 67.0 & 67.5 & 134.8 & 134.0 \\
\hline 11 & 67.5 & 67.0 & 67.5 & 67.5 & 67.3 & 67.0 & 67.5 & 110.0 & 135.0 \\
\hline 12 & 67.5 & 55.0 & 67.5 & 67.5 & 67.5 & 67.0 & 67.5 & 135.0 & 135.0 \\
\hline 13 & 67.5 & 67.5 & 67.5 & 67.5 & 67.5 & 67.0 & 67.5 & 135.0 & 135.0 \\
\hline 14 & 67.5 & 67.0 & 67.5 & 67.5 & 67.5 & 67.5 & 67.5 & 135.0 & 131.5 \\
\hline $\mathrm{T} 1$ & 910.0 & 880.0 & 902.0 & 945.0 & 911.0 & 896.0 & 937.2 & 1745.8 & 1779.0 \\
\hline T2 & 337.5 & 311.5 & 337.5 & 337.5 & 337.5 & 335.5 & 337.5 & 649.8 & 670.5 \\
\hline
\end{tabular}

Notes: $\mathrm{T} 1$ is the sum of the welfare levels over all fourteen rounds. $\mathrm{T} 2$ is the sum of the welfare levels over the last five rounds. 
the sum of the wealth minus the actual contributions. If the good is not provided, social welfare is simply the sum of the wealth because the contributions are returned when the good is not provided.

Hypotheses 1 and 2 constitute the cornerstone of our evaluation of Bagnoli and Lipman's theorem. Our most striking result is that, in the overwhelming majority of cases, the collective good is provided via voluntary contributions. Taking all fourteen periods of the five-person groups, the contributions summed to $\mathbf{1 2 . 5}$ or more in eighty-five of ninety-eight possible cases. The contribution game setting yields the Pareto efficient outcome. The theory also predicts that the contributions will sum to exactly the cost of the good, or 12.5 tokens in the five-person groups. If contributions exceed this level, all members of the group will prefer to lower their own contribution and we will not have an equilibrium. If we take exactly 12.5 tokens to be the predicted equilibrium contribution total, then we achieve this in fiftythree of ninety-eight possible cases.

We may not have a clear focal equilibrium in all of our sessions, particularly those involving groups with heterogeneous subjects. Allowing for some coordination problems, we may want to ease the criterion for achieving the predicted equilibrium. There is always the empirical issue as to when an outcome is "close enough" to the predicted outcome. We choose to define "close" as total contributions between twelve and thirteen tokens viewing the errors of excessive and insufficient contributions symmetrically. It may be argued that we should not view the errors symmetrically because the payoffs are not symmetric. If the contributions are insufficient, the public good is not provided and risk averse agents may respond by erring on the high side. In this view "close" should be defined as contributions between 12.5 and 13.0 tokens. The data we present in Table I permits the reader the option of evaluating our results on either basis. Finally, recognizing that the subjects may require some time to "learn the game," we may wish to focus our attention to the results of the last few periods, and we will discuss our results of the last five periods separately.

Under our relaxed definition (contributions in the range twelve to thirteen tokens), our subjects achieved an efficient equilibrium in seventy-five of ninety-eight cases. The impact of this behavioral classification of equilibrium is particularly apparent in the groups with rather uneven distributions of income or valuation. Under the strict definition, group 16 attains the Pareto efficient equilibrium only one time. With the less stringent definition of the equilibrium it achieves an efficient equilibrium in nine periods. A similar sort of behavior is apparent in group 12. In contrast, groups 14 and 17 hit upon an equilibrium vector of contributions quite early and maintained this throughout.

The results just described provide substantial support for hypothesis 1 : the collective good is provided and the contributions sum to the efficient level. Our results are very strong when we focus on the last five periods. The collective good is provided in thirty-three of thirty-five cases. The contributions summed to exactly 12.5 tokens in twenty-six of thirty-five cases and were in the range twelve to thirteen for all thirty-five cases. In the very last period, five of the groups contributed 12.5 tokens while the other two groups contributed thirteen tokens. We conclude that our results are consistent with supporting hypothesis 1 .

Social welfare levels are reported in Table II. The theoretical maximum is 67.5 tokens per period (945.0 for all fourteen periods and 337.5 for the last five periods). Group 14 attained the theoretical maximum over the entire session and was the only group to do so. The remaining groups were quite successful. For the last five periods, only group 12 attained less than 99 percent of the theoretical maximum. 
If hypothesis 2 is satisfied, the subjects have behaved in an individually rational manner. We have provided all subjects with incomes in excess of their valuation of the collective good making it possible for the subjects to post contributions in excess of valuation. Such behavior is, however, not individually rational since having the good under these conditions is worse than not having it. ${ }^{16}$ We report the individual contribution data in appendix B. Instances of irrational behavior (contributions in excess of valuation) are indicated by an asterisk. It is clear that irrational behavior is very infrequent and occurs primarily in the early periods. Of the 480 total observations of the five-person groups, only seven are not individually rational. All but one of these occurred in the first two rounds and could probably be attributed to subject confusion with the task in the early rounds. The behavior of the subjects assigned to ten-person groups is very similar, with only two of 280 cases exhibiting contributions which could be classified as not being individually rational. Hypothesis 2 is well supported by our data.

The subjects in group 14 posted a Pareto efficient equilibrium vector of contributions in the first period, and they maintained this vector for the duration of the session. It is interesting that the vector chosen in the first period resulted in considerable wealth transfer to subjects $14 / 1$ and $14 / 3$ at the expense of $14 / 2$, in particular. However, subject $14 / 2$ was receiving a positive net return from the provision of the public good and so wished to continue contributing four tokens, since a lower contribution, given the contributions of

16. There is another potential interpretation. There are history-dependent equilibria to the repeated game that exhibit such behavior. We thank a referee for pointing this out. However, such behavior is not observed in the last period (known to the subjects) which indicates that the players choose individually rational strategies. the other group members, would have resulted in the collective good not being provided. This is a striking example of the strength of the equilibrium predicted by the theory.

Hypothesis 3 predicted that a larger group would be as successful in providing the collective good as the small groups. However, individuals in a larger group may find it more difficult to focus on a particular equilibrium vector of contributions. Our results appear to support this conjecture. The ten-person groups (groups 20 and 21) provided the collective good in nineteen of twenty-eight possible cases. They attained the efficient outcome (which we define to be total contributions from twenty-four to twenty-six tokens) in seventeen cases. These proportions are lower than the comparable statistics for the five-person groups. We may conduct a more rigorous test by comparing the welfare levels of the five- and ten-person groups. Scaling the scores for the ten-person groups and using a Mann-Whitney test (see Conover [1980, 216-28]) on all fourteen rounds, we obtain a z-statistic of 2.22 (significant at .01 level) indicating that welfare levels are statistically higher in the five-person groups than in the tenperson groups.

If we focus only on the last five periods, we obtain different results. The z-statistic is now 0.69 (not significant) indicating that the larger groups require longer to focus on an efficient equilibrium, but that they ultimately do as well as the smaller groups.

We made a decision to assign the subjects to the same group for the duration of the session rather than to scramble them between periods. If we had chosen to assign the subjects to a different group for each period, we could have argued that all of the periods are the outcomes of the "one-shot" game. We chose our design for two reasons. First, we wanted to observe the subjects' ability to focus on an equilibrium (the speed at which the group con- 
verged to the Pareto efficient outcome) as a function of the characteristics of the group. Second, we wanted to check a prediction from the theory of repeated games.

The first requires that the subjects remain in the same group from period to period so that we are not altering the setting for any individual. Our statistical results indicate that when the subjects' valuations or incomes are very different within the group, the payoffs are lower than when the group is comprised of individuals with identical incomes and valuations. That is, those groups with more heterogeneous individuals achieve the efficient equilibrium less frequently. It appears that this effect is more pronounced when it is the valuations that differ across members of the group rather than when it is incomes that vary.

A repeated game consists of the same single-shot game being played several times by the same players. If the results of prior periods are always known by all the players (as is the case when we announce the sum of the contributions from the group in each period) then each period defines a subgame of the full (or repeated) game. An equilibrium in the repeated game is sensible only if it induces an equilibrium in every subgame. Such equilibria are called subgame perfect.

A well-known result in finitely repeated games is that one (subgame perfect) equilibrium consists of repeating the same single-play (or one-shot) equilibrium in each period of the repeated game. That is, there is no "signalling" by playing strategies, which are not equilibrium strategies in the one-shot game, in the early periods with the intention of causing the other players to play specific strategies later in the game. Repeating the same single-play equilibrium in our laboratory setting requires that the subjects post the same vector of contributions in each round and that the sum of the contributions equals the cost of the good with no individual contributing more than his or her valuation.
By having the subjects remain in the same group, we can test whether or not this result is obtained in our experiments. We caution the reader that this is a very weak comparison because of the multiplicity of the single-period equilibria that we discussed earlier. This multiplicity means that the set of subgame perfect Nash equilibria is very large. Our data does not support such an equilibrium. While group 14 's behavior is consistent, no other group's vector of contributions remained unchanged throughout all fourteen rounds of the game. Our results are suggestive, but further work must be done before this issue can be resolved.

\section{CONCLUSION}

We began with two objectives. Our first was to subject a voluntary public good contribution mechanism to empirical testing in a controlled setting. A second objective was to evaluate the application in theoretical work of some proposed refinements to the Nash equilibrium concept.

The theoretical work of Bagnoli and Lipman [1989] provides a very clear empirical implication. If we offer a well-defined group of people the opportunity to contribute to the provision of a public good when the cost of the good, the payoffs to those in the group, and the initial wealth positions of those in the group are all common knowledge, then the Pareto efficient outcome will emerge. If their collective valuations exceed the cost of the public good, the members of the group will voluntarily contribute exactly the cost of the good. In our laboratory setting we obtain just this result.

Some might object that a mechanism requiring such complete information is of limited interest to the problem of efficient provision of public goods in the field. However, the anecdotal evidence we cited at the beginning of this paper suggests that such mechanisms can be, and have been, successfully applied in the field. At 
this time we have tested the mechanism under the strong informational conditions imposed by the theory since we felt it was important to begin with a test of the theory as it stands. Future research could be devoted to systematic relaxation of these informational conditions to allow investigation of the extent to which the theoretical predictions are sensitive to the requirement that the individual players in the game possess complete information.

That our subjects are able to achieve the Pareto efficient equilibrium postulated in the theory suggests that individuals are capable of implementing some sophisticated refinements to the Nash equilibrium. Other researchers, such as Camerer and Weigelt [1988], have also found that laboratory subjects are capable of implementing certain refinements. This is good news for game theory since the use of refinements is often necessary to eliminate some equilibria that are not economically sensible.

\section{APPENDIX A}

\section{Experimental Instructions}

This is an experiment in the economics of decision making. Several research organizations have provided funds for this research. The instructions are simple and, if you follow them carefully and make good decisions, you may earn a considerable amount of money. This money will be paid to you in cash at the end of the experiment.

\section{Organization:}

You have been organized into groups each of five or ten persons. Each group will consist of the same five or ten persons for the duration of the session. The session will last for fourteen periods. In each period you will be required to make a decision and your total income will depend on these decisions.

The specific identities of the other persons in your group will not be revealed to you. You may not communicate with anyone else in the room during the session.

The actual number of persons in your group, along with other information, is re- ported on a set of information slips that have been provided to you. You have been given one slip for each period of the session.

At the beginning of each period you will receive an income in tokens. These tokens will be exchanged for money at a rate stated on your information slips. Also provided on these slips is the income of each of the other persons in your group. This is private information; you are not to reveal it to anyone else in the room.

You will be asked to post a contribution in each period. You will have three minutes to enter your contribution. You may enter any contribution from zero up to the amount of your income for the entire period. Contributions in excess of your income will not be accepted. Enter your contribution in the space on the information slip provided. You may contribute part tokens, e.g., 4.5 tokens.

Once the contributions have been entered, the slips will be collected by the persons running the experiment. If the sum of the contributions of the persons in your group meets or exceeds the threshold level that is stated on your information slips, you will each receive an additional bundle of tokens. The size of this addition for the group, and for yourself, is also stated on the information slips. Your total income for the period will be your initial income plus the additional tokens minus your contribution.

If the sum of the contributions is less than the threshold level the additional tokens will not be provided. In this event, your contributions will be returned to you and your total income for the period will simply be your original income.

At the end of each period, the persons running the experiment will inform you whether your group has obtained the additional tokens. The total contributions of your group, but not the contributions of individual members will be posted on the board.

A set of information slips has been prepared for you. You have one slip for each period. On each slip your ID number and the period appear in the upper right corner. As well, the slip tells you your income for the current period, the incomes of the other members of the group, the number of persons in your group, and the share of the additional tokens that will go to each member of your group. Finally, the slip contains a blank where you are required to enter your contribution for the period. An example slip and session are presented below. 
EXAMPLE INFORMATION SLIP

Period \# 1

ID \# 29

Number of persons in your group is 5 .

Threshold contribution of your group is $\mathbf{1 2 . 5}$ tokens.

If this contribution is met or exceeded, the group will receive an additional 25 tokens. Your share of the additional tokens is 5 tokens. All members of the group receive the same share.

$\begin{array}{ll}\text { Your Income } & 4.00 \text { tokens } \\ \text { Other persons' incomes } & 4.00 \text { tokens } \\ & 4.00 \text { tokens } \\ & 4.00 \text { tokens } \\ & 9.00 \text { tokens }\end{array}$

Your contribution
That is, your income is 4.00 tokens for this period. Of the others in your group, three have an income of 4.00 and one has an income of 9.00 .

Session: The required total contribution is 12.5 tokens. Say you contribute 2.00 tokens. Now, if the total is at least 12.5 tokens, then you will receive 5.00 tokens plus your initial income of 4.00 tokens less your 2.0 tokens contribution. Your total income for the period is 7.00 tokens.

If the total contribution from your group is less than 12.5 tokens, you will receive your initial income of 4.00 tokens for the period regardless of your own posted contribution. That is, the additional tokens will not be provided in this period and your posted contribution will be returned to you.

\section{INCOMES AND VALUATIONS}

\begin{tabular}{|c|c|c|c|c|c|c|c|}
\hline $\begin{array}{l}\text { Group } \\
\text { Number }\end{array}$ & $\begin{array}{c}\text { Subject } \\
\text { ID }\end{array}$ & Income & Valuation & $\begin{array}{l}\text { Group } \\
\text { Number }\end{array}$ & $\begin{array}{c}\text { Subject } \\
\text { ID }\end{array}$ & Income & Valuation \\
\hline 11 & $\begin{array}{l}11 / 1 \\
11 / 2 \\
11 / 3 \\
11 / 4 \\
11 / 5\end{array}$ & $\begin{array}{l}11.0 \\
11.0 \\
11.0 \\
11.0 \\
11.0\end{array}$ & $\begin{array}{l}5.0 \\
5.0 \\
5.0 \\
5.0 \\
5.0\end{array}$ & 17 & $\begin{array}{l}17 / 1 \\
17 / 2 \\
17 / 3 \\
17 / 4 \\
17 / 5\end{array}$ & $\begin{array}{l}11.0 \\
11.0 \\
11.0 \\
11.0 \\
11.0\end{array}$ & $\begin{array}{l}6.0 \\
6.0 \\
6.0 \\
6.0 \\
1.0\end{array}$ \\
\hline 12 & $\begin{array}{l}12 / 1 \\
12 / 2 \\
12 / 3 \\
12 / 4 \\
12 / 5\end{array}$ & $\begin{array}{r}16.0 \\
16.0 \\
8.0 \\
8.0 \\
7.0\end{array}$ & $\begin{array}{l}5.0 \\
5.0 \\
5.0 \\
5.0 \\
5.0\end{array}$ & 20 & $\begin{array}{l}20 / 1 \\
20 / 2 \\
20 / 3 \\
20 / 4 \\
20 / 5 \\
20 / 6\end{array}$ & $\begin{array}{l}11.0 \\
11.0 \\
11.0 \\
11.0 \\
11.0 \\
11.0\end{array}$ & $\begin{array}{l}5.0 \\
5.0 \\
5.0 \\
5.0 \\
5.0 \\
5.0\end{array}$ \\
\hline 13 & $\begin{array}{l}13 / 1 \\
13 / 2 \\
13 / 3 \\
13 / 4 \\
13 / 5\end{array}$ & $\begin{array}{r}16.0 \\
14.0 \\
11.0 \\
7.0 \\
7.0\end{array}$ & $\begin{array}{l}5.0 \\
5.0 \\
5.0 \\
5.0 \\
5.0\end{array}$ & & $\begin{array}{l}20 / 7 \\
20 / 8 \\
20 / 9 \\
20 / 10\end{array}$ & $\begin{array}{l}11.0 \\
11.0 \\
11.0 \\
11.0\end{array}$ & $\begin{array}{l}5.0 \\
5.0 \\
5.0 \\
5.0\end{array}$ \\
\hline 14 & $\begin{array}{l}14 / 1 \\
14 / 2 \\
14 / 3 \\
14 / 4 \\
14 / 5\end{array}$ & $\begin{array}{r}12.0 \\
12.0 \\
12.0 \\
12.0 \\
7.0\end{array}$ & $\begin{array}{l}5.0 \\
5.0 \\
5.0 \\
5.0 \\
5.0\end{array}$ & 21 & $\begin{array}{l}21 / 1 \\
21 / 2 \\
21 / 3 \\
21 / 4 \\
21 / 5 \\
21 / 6\end{array}$ & $\begin{array}{r}16.0 \\
16.0 \\
16.0 \\
16.0 \\
8.0 \\
8.0 \\
8.0\end{array}$ & $\begin{array}{l}5.0 \\
5.0 \\
5.0 \\
5.0 \\
5.0 \\
5.0\end{array}$ \\
\hline 15 & $\begin{array}{l}15 / 1 \\
15 / 2 \\
15 / 3 \\
15 / 4 \\
15 / 5\end{array}$ & $\begin{array}{l}11.0 \\
11.0 \\
11.0 \\
11.0 \\
11.0\end{array}$ & $\begin{array}{r}10.0 \\
10.0 \\
2.0 \\
2.0 \\
1.0\end{array}$ & & $\begin{array}{l}21 / / 8 \\
21 / 9 \\
21 / 10\end{array}$ & $\begin{array}{l}8.0 \\
8.0 \\
7.0 \\
7.0\end{array}$ & $\begin{array}{l}5.0 \\
5.0 \\
5.0 \\
5.0\end{array}$ \\
\hline 16 & $\begin{array}{l}16 / 1 \\
16 / 2 \\
16 / 3 \\
16 / 4 \\
16 / 5\end{array}$ & $\begin{array}{l}11.0 \\
11.0 \\
11.0 \\
11.0 \\
11.0\end{array}$ & $\begin{array}{r}10.0 \\
8.0 \\
5.0 \\
1.0 \\
1.0\end{array}$ & & & & \\
\hline
\end{tabular}




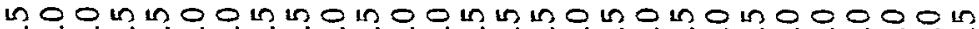

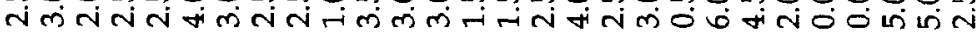

in 0 o in in in 0 in in o in 00 in in in o in 0 in 0 in 00000 in तें

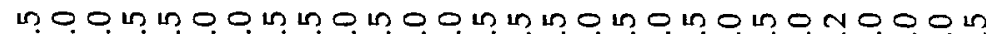

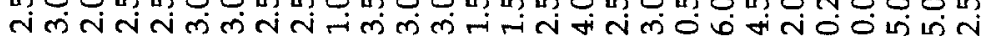

in 00 in in 00 in in 0 in 00 in in in 0 in 0 in 0 in 00000 in ले ते

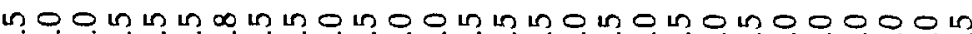
लm

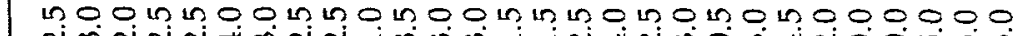
Nलn N

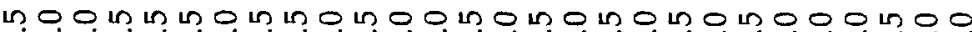

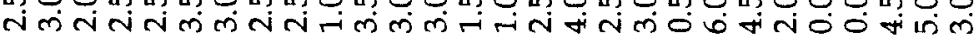

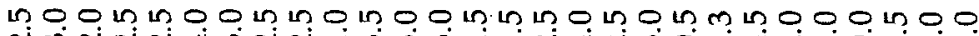

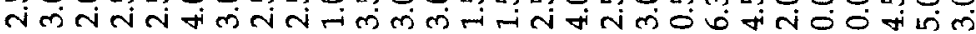

in in 0 in in in 0 in 00 in 00 in in in 0 in 0 in $\mathrm{m}^{2}$ in 000000

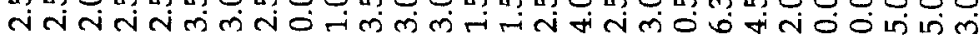

no o in in in o in in o o in o o in in 0 in 0 in in in

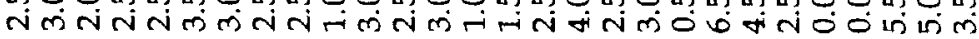

in 000 in in in in in 000 in in in in 0 in 0 in 00000 in 0 in

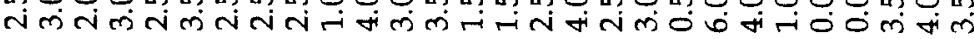

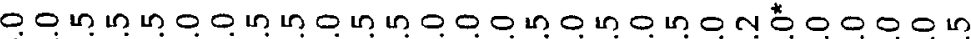

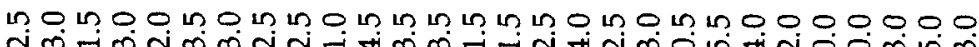
ले भim

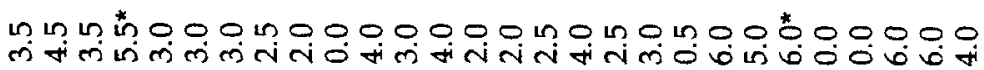

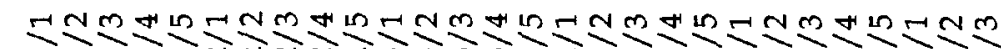

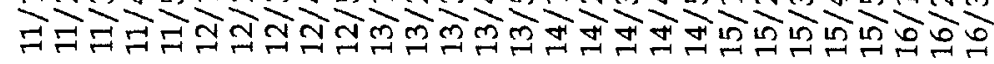




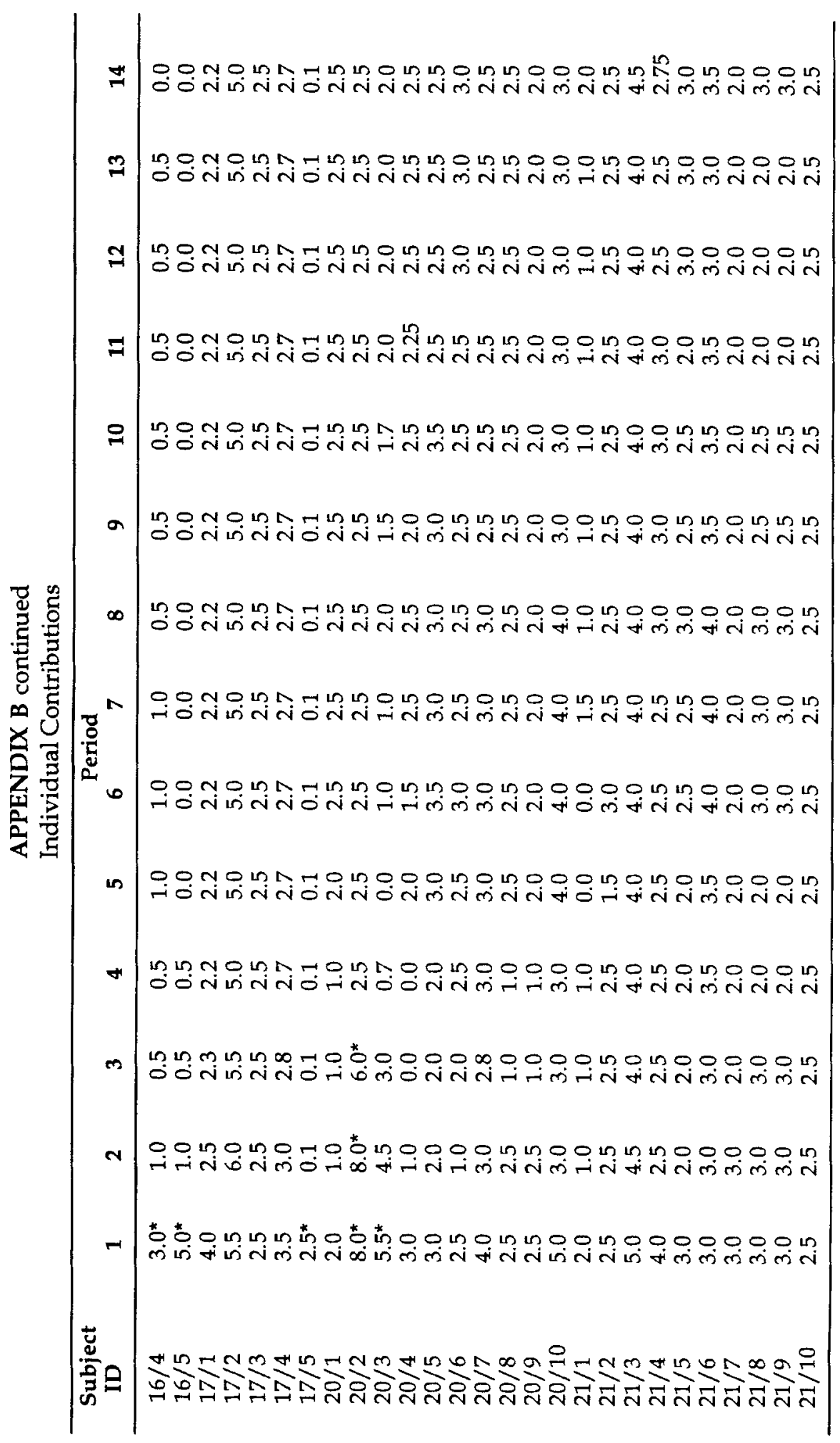




\section{REFERENCES}

Andreoni, J. "Impure Altruism and Donations to Public Goods." University of Wisconsin Working Paper, 1987.

"Why Free Ride? Strategies and Learning in Public Goods Experiments." Joumal of Public Economics, December 1988, 291-304.

Bagnoli, M. and B. Lipman. "Provision of Public Goods: Fully Implementing the Core Through Private Provision." Review of Economic Studies, October 1989, 583-602.

Bergstrom, T. R., L. Blume, and H. Varian. "On the Private Provision of Public Goods." Journal of Public Economics, February 1986, 25-39.

Borcherding, T. E. "Competition, Exclusion, and the Optimal Supply of Public Goods." Journal of Law and Economics, April 1978, 111-132.

Camerer, C. A. and K. Weigelt. "Experimental Tests of a Sequential Equilibrium Reputation Model." Econometrica, January 1988, 1-36.

Coase, R. "The Lighthouse in Economics." Journal of Law and Economics, October 1974, 357-76.

Conover, W. J., Practical Nonparametic Statistics, 2nd ed. New York: John Wiley \& Sons, 1980.

Cornes, R. and T. Sandler. "The Simple Analytics of Pure Public Goods Provision." Economica, February 1985a, 103-16.

"On the Consistency of Conjectures with Public Goods." Journal of Public Economics, June 1985b, 125-29.

Dawes, R. M., J. M. Orbell, R. T. Simmons, and A. J. C. van de Kragt. "Organizing Groups for Collective Action." American Political Science Review, December 1986, 1171-185.

Demsetz, H. "The Private Production of Public Goods." Joumal of Law and Economics, October 1970, 293-306.

Frohlich, N. and J. Oppenheimer. "I Get By With a Little Help From My Friends." World Politics, October 1970, 104-20.
Frohlich, N., T. Hunt, J. Oppenheimer, and R. H. Wagner. "Individual Contributions for Public Goods." Journal of Conflict Resolution, June 1975, 310-29.

Hirshleifer, J. "From Weakest Link to Best-Shot: The Voluntary Provision of Public Goods." Public Choice, 41(3), 1983, 371-86.

Isaac, R. M., K. F. McCue, and C. R. Plott. "Public Goods Provision in an Experimental Environment." Journal of Public Economics, February 1985, 51-74.

Palfrey, T. and H. Rosenthal. "Participation and the Provision of Discrete Public Goods: A Strategic Analysis." Journal of Public Economics, July 1984, 171-93.

"Private Incentives in Social Dilemmas: The Ef fects of Incomplete Information and Altruism." Journal of Public Economics, April 1988, 309-32.

Samuelson, P. A. “The Pure Theory of Public Expenditures." Review of Economics and Statistics, November 1954, 387-89.

Selten, R. "Reexamination of the Perfectness Concept for Equilibrium Points in Extensive Games." International Journal of Game Theory, 4(1), 1975, 25-55.

Shubik, M. Game Theory and the Social Sciences. Cambridge, MA: MIT Press, 1982.

Smith, V. L. "Experimental Economics: Induced Value Theory." American Economic Review: Papers and Proceedings, May 1976, 274-79.

Thompson, E. A. "The Perfectly Competitive Production of Collective Goods." Review of Economics and Statistics, February 1968, 1-12.

van de Kragt, A. J. C., J. M. Orbell, and R. M. Dawes. “The Minimal Contributing Set as a Solution to Public Goods Problems." American Political Science Review, March 1983, 112-22.

van Damme, E. Refinements of the Nash Equilibrium Concept. Berlin: Springer-Verlag, 1983. 